\title{
LEARNING GAINS RELATED TO THE USE OF MOBILE RESOURCES FOR UNDERGRAD PHYSICS COURSES
}

\author{
Víctor Robledo-Rella, Luis Neri, Andrés González-Nucamendi and Julieta Noguez \\ Escuela de Ingeniería y Ciencias, Tecnológico de Monterrey, Campus Ciudad de México \\ Calle del Puente 222, Ejidos de Huipulco, Tlalpan, Cd. de México, CP 14380
}

\begin{abstract}
In this paper we present the results derived from a project aimed to study the learning gains obtained by undergrad engineering students that used two mobile learning resources (in video format). We conducted our study over a 6-year time interval applying pre-test and post-test instruments to both experimental groups (which used the mobile resources) and control groups (which did not). Our sample consisted of $N=793$ students and we found that the experimental group obtained learning gains about $26 \%$ higher than those of the control group. We found this difference to be meaningful, with $p$-values around 0.022 . Perception questionnaires applied to the control groups showed that most of the students consider that the use of mobile resources improved their concept-comprehension and helped them to develop their problem-solving skills.
\end{abstract}

\section{KEYWORDS}

Learning Gains, Physics, Student Perception, Educational Innovation

\section{INTRODUCTION}

The use of mobile technologies has changed the way we interact and communicate (Kukulska-Hulme, 2007; Ally and Tsinakos, 2014). Nowadays, it is very common for students to have access to different sources of knowledge on the Internet, in many cases in video format. One example may be the so called YouTube channels. Using video and multimedia resources in on-line systems is nowadays a must practice and turns out to be quite natural for current new-millennial students, from elementary school to undergrad and graduate studies. Gamification has also become a major trend in educational institutions and have a strong potential in years to come. One of the main advantages of using videos for instructional purposes is that the user can watch them anywhere, anytime, as many times as needed and can be paused if necessary in difficult or fast-paced parts of the video.

To the best of our knowledge, however, and despite the importance of using (mobile) videos for academic purposes, there has been little effort aimed to set a quasi-experimental environment where the effectiveness of using such online material can be assessed (Cochrane, 2014 and Cochrane \& Narayan, 2016). On one hand, some authors have reported that the use of mobile learning (henceforth $m L$ ) resources have a positive impact on learning outcomes (Wu, et.al. 2012; Kearney, et.al. 2012; Merayo, et.al., 2015). However, on the other hand, some authors have pointed out the potential risk of using mobile devices, since they can easily become a distractor in the classroom (Robledo, 2012).

A decade ago, the Tecnológico de Monterrey launched a large-scale mobile learning model in which each new student was given a mobile device (back then it was a Blackberry) in order to deliberately incorporate the use of mobile resources (mainly in video-format) to deliver course content, both in high school and undergrad courses. Since then, our research group started an initiative aimed to design, implement and evaluate the impact that using $\mathrm{mL}$ resources may have in student outcomes. The contribution of this paper is then to share with the $\mathrm{mL}$ community our findings regarding this project. In Sec. 2 we comment on the general aspects of the $\mathrm{mL}$ resources design. In Sec. 3 we describe the methodology employed in this study, and in Sec. 4 we present our main results regarding the learning gains attained by students whom used the $\mathrm{mL}$ resources in their Physics courses (the Experimental group) as compared to those obtained by students whom did not used the resources (the Control group). We also summarize our findings regarding the general 
perception of the Experimental students about the use and benefits of using $\mathrm{mL}$ resources. Previous results have been reported by Robledo-Rella et al. 2010; Chirino et al. 2010; Robledo-Rella et al. 2011). Complementary and extended results to this paper are presented by Robledo-Rella et al. 2017.

\section{DESIGN OF ML RESOURCES}

As mention above, we designed several $\mathrm{mL}$ resources in video-format to be used in Physics I (Classical Mechanics) courses in our institution in order to cover the main themes of the course (from vectors in 3D to rotational dynamics). However, for this study we focused ourselves in only two main themes: $i$ ) Particle Dynamics (Newton's $2^{\text {nd }}$ law and Free Body Diagram) and ii) Conservation of linear momentum. The design of these $\mathrm{mL}$ resources was carried out by professors of the Science Department with the support of instructional designers whom helped to guarantee that the final product videos were adequate and attractive to the students regarding $i$ ) aesthetic, ii) sound and graphics considerations, and iii) length and content displayed. Each video has a framing introduction, a brief description of the main concepts (the theory) and ends with a proposed exercise for the student (the practice) so to recap on what was just learned.

Our first resource was a 5-minute video showing the student how to build a Free Body Diagram (hereafter FBD) and how to apply Newton $2^{\text {nd }}$ law to a block resting on an incline and being acted by an external force. Regarding the theme of Conservation of Linear Momentum (hereafter CLM) we designed two short videos, one explaining general aspects of linear momentum in everyday life and the other explaining the conditions for linear momentum conservation and the different types of collisions in 1D (this last video included measuring experimental cart-collisions in the lab). At the end of the video, the students are also asked to answer some summarizing questions. The CLM mL resources were later redesigned so to improve both visual and audio elements (Neri et al. 2016).

\section{EXPERIMENTAL METHODOLOGY}

As mentioned above, we implemented a pre-test/post-test methodology applied to Experimental and Control groups. The Experimental groups had access to the $\mathrm{mL}$ resources for about two weeks using their mobile devices (either smartphones or tablets), while the Control group was given similar material in a traditional way. In both cases, the professor gave her lectures as usual. In order to minimize the professor-variable, we guaranteed that the professor had, for any given semester, at least one Experimental group and one Control group. The selection of both the Experimental and Control groups were random before the start of the semester.

Both the FBD and CLM mL resources were applied from 2009-II to 2015-I terms. Table 1 below shows the number of students participating in the Experimental and Control groups, both for the FBD and CLM mL resources, respectively. We analyzed $N=423$ student results for the FBD and $N=370$ students for the CLM $\mathrm{mL}$ resource. Before analyzing our data we cleaned our sample due to misclassified students between the Control and Experimental groups (about 2\% of the sample).

The pre-test and post-test were basically the same and were carefully designed so to measure the fulfillment of the leaning objectives stated in each $\mathrm{mL}$ resource. The pre-test was applied to the whole population before the Experimental groups had access to the $\mathrm{mL}$ resources. The post-test was also applied to the whole population after the Experimental group interacted with the $\mathrm{mL}$ resources, about 2-3 weeks after the pre-test was applied. In this way we were able to assign to each student a learning gain defined by: $G_{\mathrm{i}}=$ Post $_{\mathrm{i}}-\operatorname{Pre}_{\mathrm{i}}$, where Post $\mathrm{i}_{\mathrm{i}}$ and Pre $\mathrm{i}_{\mathrm{i}}$ are the post-test and pre-test grades of student $i$. The pre-test and post-test were applied to all students during class time in the classroom and each lasted about $15-20$ minutes. Each test was graded in a $0-100$ scale following a well-defined rubric.

In order to proceed with the analysis, we defined for each group its average learning gain as: $\langle G\rangle=(1 / N)$ $\Sigma G_{\mathrm{i}}$, where $N$ is the number of students in each section per semester. 


\section{RESULTS AND DISCUSSION}

Our main results are summarized in Table 1 both for the FDB and CLM mL resources. We show the number of sections/semesters in which the measurements were taken, the number of students, the average pre-test, average post-test and average learning gain, both for the Experimental and Control groups. For the sake of clarity, we do not indicate the standard deviations of the pre-test and post-test, which were typically of about 15 points.

Table 1. Average pre-test, post-test and learning gains for the Experimental and Control groups for the FBD and CLM $\mathrm{mL}$ resources

\begin{tabular}{lccccc}
\hline & $N$ sections & $N$ students & $\langle$ Pre $\rangle$ & $\langle$ Post $\rangle$ & $\langle G\rangle$ \\
\hline FDB Experimental & 13 & 253 & 34 & 60 & 26 \\
FBD Control & 11 & 170 & 32 & 51 & 19 \\
& & & & & \\
CLM Experimental & 10 & 208 & 34 & 61 & 27 \\
CLM Control & 9 & 162 & 35 & 51 & 16 \\
\hline
\end{tabular}

As can be seen form Table 1, the average pre-test is similar for the Experimental and Control groups, as expected, given that these groups were randomly chosen.

In order to help us to visualize the differences between the Experimental and Control groups, we show in Figure 1 the "Hake diagram" of the average learning gain $\langle G\rangle$ vs. the average pre-test $\langle$ Pre $\rangle$ of each of the 24 sections considered for the FBD $\mathrm{mL}$ resource and the 19 sections considered for the CLM mL resource, respectively (Hake, 1988).
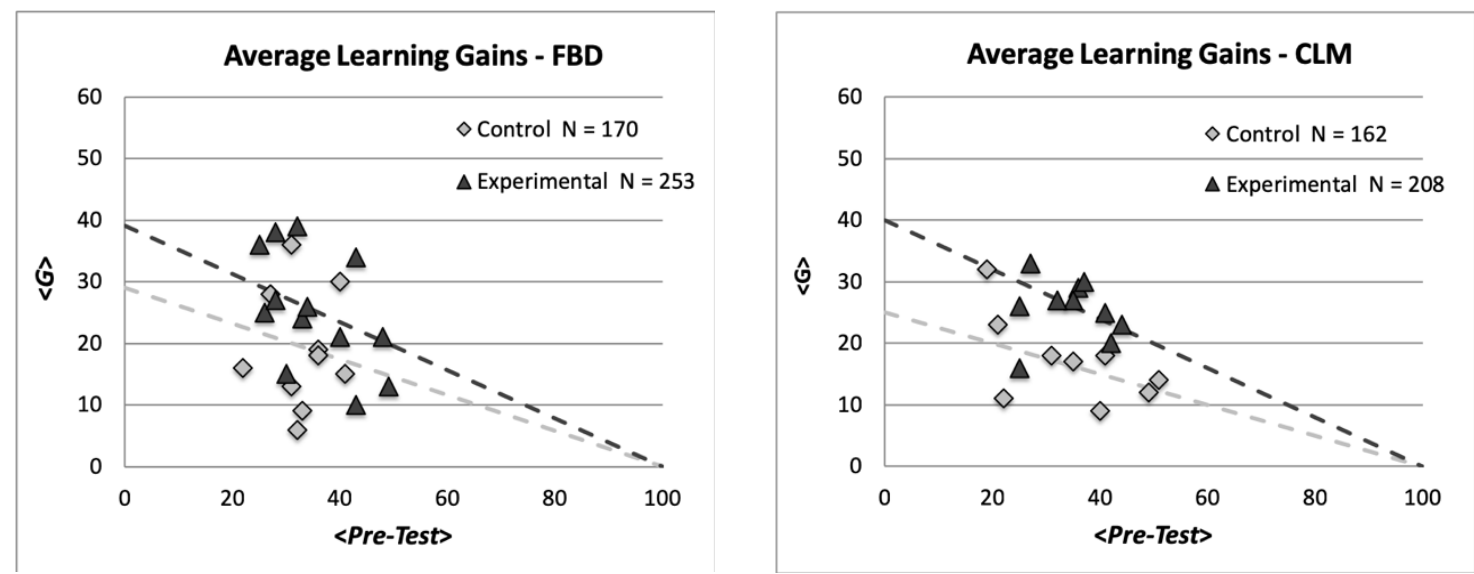

Figure 1. "Hake diagram" of average learning gain $\langle G\rangle$ vs. average pre-test $\langle$ Pre $\rangle$ for each of the studied sections for the FBD and CLM $\mathrm{mL}$ resources, respectively

As can be seen from these plots, the Experimental sections tend to populate larger values of $\langle G\rangle$, for a given pre-test, as compared to the Control sections.

We performed a $t$-test to the individual student learning gains $\left(N_{\mathrm{FBD}}=423\right.$ and $\left.N_{\mathrm{CLM}}=370\right)$ in order to determine if the differences between the Experimental and Control groups were meaningful. For the FBD we found $p$-values of $p=0.0022$, making the difference meaningful for this resource. However, for the CLM we found $p=0.045$, which means that the difference is barely meaningful.

From Table 1, we can see that, for the FBD mL resource, the average learning gain for the Experimental group is about 7-8 points higher (in a $0-100$ scale) than that for the Control group. For the CLM mL resource, this difference is up to 11 points. 
Although it is not shown in Table 1, we found that, contrary to any reasonable expectation, some students within our sample got negative learning gains (that is $\operatorname{Post}_{\mathrm{i}}<P r \mathrm{P}_{\mathrm{i}}$ ). We found that the percentage of students with negative learning gains was about $3 \%$ smaller in the Experimental than in the Control groups.

As mentioned above, we also applied a perception questionnaire (with a 5-step Likert scale) to find out what was the overall student perception about the usefulness of the $\mathrm{mL}$ resources to enhance concept-understanding and the development of problem-solving skills. We collected $N_{\mathrm{P}}=203$ student responses and our main results are summarized in Table 2 below, where we have binned the answer in only three levels (Agreement, Neutral y Disagreement). As we can see, the use of $\mathrm{mL}$ resources has a positive approval among most of the students.

Table 2. Perception questionnaire main results $\left(N_{\mathrm{P}}=203\right)$

\begin{tabular}{lccc}
\hline & Agreement & Neutral & Disagreement \\
\hline mL helps to understand concepts & $67 \%$ & $23 \%$ & $11 \%$ \\
mL promotes problem-solving skills & $61 \%$ & $23 \%$ & $16 \%$ \\
\hline
\end{tabular}

\section{CONCLUSIONS}

We presented a self-consistent study spanning 6-years about the use of mobile learning resources and their impact in the learning process. In general, we found encouraging (and expected) results indicating that the use of video materials favored the learning process of Physics concepts as measured by means of a pre-test/post-test instrument, with increased learning gains by as much as $26 \%$, being this a meaningful difference. It is worth mentioning that the general teaching methods used by the professors lecturing these Physics courses did not change substantially along this 6-year time span, so we consider that the observed differences in the learning gains between the Experimental and Control groups are mainly due to the use of the $\mathrm{mL}$ resources.

The use of mobile resources in education, in the form of short videos has still a strong acceptance among most students and should be considered for teachers when preparing their instructional design. Given the current wide acceptance and necessity in our daily lives of the use of smartphones, tablets, the Cloud and Web 2.0 services, it is expected that enforcing these channels of communication will continue to be a major educational feature. Therefore, we expect that the use of mobile devices related to gamification will certainly increase in the forthcoming years.

\section{ACKNOWLEDGEMENT}

The authors would like to acknowledge the financial and the technical support of Writing Lab, TecLabs, Tecnologico de Monterrey, Mexico, in the production of this work.

We also acknowledge previous support from the Department of Science and the School of Engineering and Science of the Tecnologico de Monterrey, Campus Ciudad de Mexico, to produce the video-materials used along this project and to carry on the experimental part of this work.

\section{REFERENCES}

Ally M. and Tsinakos, A. 2014. Introduction: Enhancing access to education with mobile learning. In: Ally, M. and Tsinakos, A. (eds.) Increasing access through mobile learning. Perspectives on open and distance learning. Vancouver: Commonwealth of Learning, pp. 1-4. ISBN 978-1-894975-64-3

Chirino, V., Noguez, J., Neri, L., Robledo-Rella, V., \& Aguilar, G. Mobile Science. Students' Perception about the Use of Mobile Devices in Self-Managed Learning Activities and Learning Gains Related to Mobile Learning Resources. In m-Science, Sensing, Computing and Dissemination. Eds. E. Canessa \& M. Zennaro, The Abdus Salam International Centre for Theoretical Physics, pp. 225-241. 2010. ISBN 92-95003-43-8 
Cochrane, T.2014. Critical success factors for transforming pedagogy with mobile Web 2.0. British Journal of Education, 45(1), pp. 65-82, DOI: 10.1111/j.1467-8535.2012.01384.x

Cochrane, T. and Narayan, V. 2016. Mobile social media: Redefining professional development and collaborative scholarship. In: D. Churchill, J. Lu, T.K. Chiu (eds.) Mobile learning design: Theories and application. Springer Singapore, pp. 43-62. DOI: 10.1007/978-981-10-0027-0_3

Hake, R.R., 1988. Interactive-engagement versus traditional methods: A six-thousand-student survey of mechanics' test data for introductory physics courses. Am. J. Phys. 66(1), 1988, pp. 64-74. DOI: http://dx.doi.org/10.1119/1.18809

Kearney, M., Schuck, S., Burden, K. and Aubusson, P. 2012. Viewing mobile learning from a pedagogical perspective. Research in Learning Technology, 20, pp. 1-17. DOI: 10.3402/rlt.v20i0.14406

Kukulska-Hulme, A. 2007. Mobile usability in educational contexts: what have we learnt? International Review of Research in Open and Distance Learning, 8(2), pp. 1-16. ISSN: 1492-3831

Merayo, N., Prieto, P., Duran, R.J., Aguado, J.C., Fernández, P., De Miguel, I., Lorenzo, R.M. and Abril, E. J. 2015. M-learning and e-learning interactive applications to enhance the teaching-learning process in optical communications courses. International Journal of Engineering Education. 31(2), pp. 574-588. ISSN 0949-149X

Neri, L., Morales, J., Noguez, J. \& Aguilar-Sánchez, G. Engaging Students to Learn Physics and Mathematics through Short High Quality M-Learning Resources: Design and Implementation Recommendations, In Handbook of research on mobile devices and applications in higher education settings, IGI Global book series Advances in Mobile and Distance Learning, L. Briz-Ponce, Juanes-Mendez, F.J. Garcia- Peñalvo (eds.) (ISSN: 2327-1892; eISSN: 2327-1906)

Robledo, S.J. 2012. Mobile devices for learning: what you need to know. George Lucas Educational Foundation. Edutopia, http://eric.ed.gov/?id=ED539398, Accessed 1 January 2019

Robledo-Rella, V., Neri, L., Chirino, V., Noguez, J., \& Aguilar, G. Design, Implementation and Evaluation of Mobile Learning Resources. IADIS International Conference on Mobile Learning, Porto, Portugal, March, 2010, pp. 377-379, ISBN: 978-972-8924-99-7

Robledo-Rella, V., Neri, L., Aguilar, G. \& Noguez, J. Design and evaluation of mobile learning resources considering student learning styles. IADIS International Conference on Mobile Learning, Ávila, Spain, March, 2011, pp. 246-250, ISBN: 978-972-8939-45-8

Robledo-Rella, V., Neri, L., Noguez, J., \& González-Nucamendi, A. The use of Mobile Learning Resources to Enhance Physics Learning for Engineering Students: A Six Year Study. International Journal of Engineering Education, 33(6A), pp. 1940-1952, 2017; 0949-149X/91

Wu, W.H., Wu, Y.C.J., Chen, C.Y., Kao, H.Y., Lin, C.H and Huang, S.H., 2012. Review of trends from mobile learning studies: A meta-analysis. Computers \& Education, 59(2), pp. 817-827. DOI: 10.1016/j.compedu.2012.03.016 